Synthesis of Natural

Products and

Potential Drugs

\section{Synthesis of (-)-Longeracinphyllin A}<smiles>CC1=CC(=O)CCC1O</smiles>

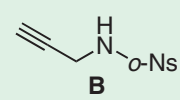

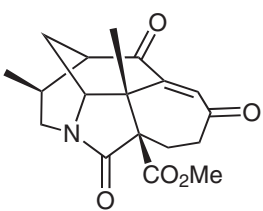

G

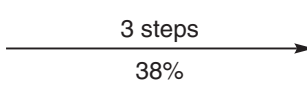<smiles>C#CCN(O[Na])C1CC=C(OCC)C=C1C</smiles>

tri-tert-butylpyrimidine (10 mol\%)

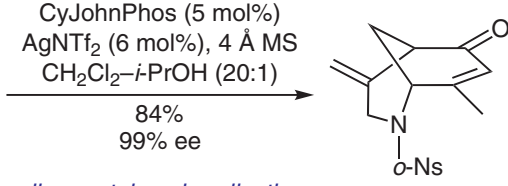

silver-catalyzed cyclization

\section{Key words}

daphniphyllum alkaloids

cyclization

intramolecular conjugate addition

asymmetric hydrogenation

[3+2] cycloaddition

1. KHMDS, PhSeBr, THF $-78^{\circ} \mathrm{C}$

2. $\mathrm{MCPBA}, \mathrm{CH}_{2} \mathrm{Cl}_{2},-78^{\circ} \mathrm{C}$ 3. DABCO, air, $\mathrm{MeCl}, 40^{\circ} \mathrm{C}$

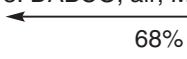

6-exo-dig

1. Cul, $\mathrm{Zn}, \mathrm{pyr}-\mathrm{H}_{2} \mathrm{O}(1: 4)$

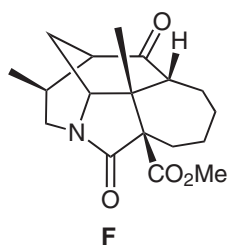
sonication, $35^{\circ} \mathrm{C}$

2. $[\mathrm{Rh}(\mathrm{cod}) \mathrm{Cl}]_{2}(2.5 \mathrm{~mol} \%)$ $\mathrm{AgBF}_{4}(7.5 \mathrm{~mol} \%)$

$\mathrm{Ph}_{3} \mathrm{P}(5 \mathrm{~mol} \%), \mathrm{H}_{2}$ (1 atm) $\stackrel{\mathrm{CH}_{2} \mathrm{Cl}_{2}}{\longleftarrow}$

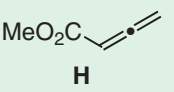

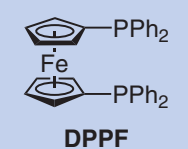
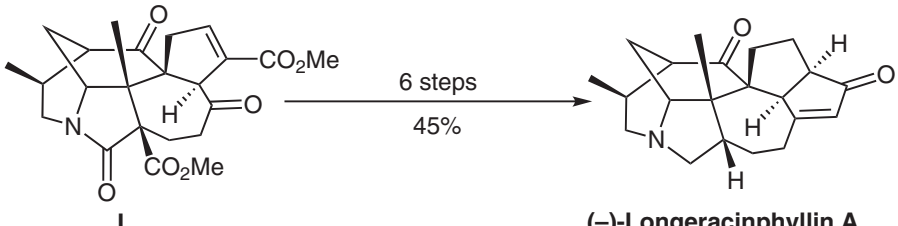

(-)-Longeracinphyllin A

Significance: Alkaloid natural products isolated from leaves and roots of the Daphniphyllum genus of plants are widely used in Chinese herbal medicine. The first and asymmetric total synthesis of $(-)$-longeracinphyllin A, a member of this structurally complex family of natural products, was accomplished by Li and co-workers. The significance of the approach chosen by the authors lies in the rapid construction of intermediate $\mathbf{D}$ and assembly of structurally advanced tetracycle $\mathbf{F}$ in large quantities. This enables elegant completion of the highly challenging target by [3+2] cycloaddition in just 21 synthetic steps.
Comment: Borrowing from their previously established route for a related natural product (Nat. Chem. 2013, 5, 679), the authors gained expedient entry to the core of the target from abundant precursor $\mathbf{C}$ by silver-catalyzed 6-exo-dig cyclization, intramolecular conjugate addition, and asymmetric olefin hydrogenation. Acquisition of enone G proved crucial as this electron-deficient substrate was found to undergo diphosphine-promoted [3+2] cycloaddition with allenoate $\mathbf{H}$, while other olefins would not react. The pentacyclic lactam I was carried on forward to render (-)-longeracinphyllin A. 